\title{
Generation of $\mathrm{O}_{2}$-Permeation Barrier during the Gamma-Irradiation of Polyethylene/Ethylene-Vinyl Alcohol/Polyethylene Multilayer
} Film

\author{
Samuel Dorey, ${ }^{* \dagger}{ }^{\dagger}$ Fanny Gaston, ${ }^{\dagger}$ Nina Girard-Perier, ${ }^{\dagger, \ddagger, \S \odot ~ N a t h a l i e ~ D u p u y, ~}{ }^{*, \ddagger}$ \\ Sylvain R. A. Marque, ${ }^{*},{ }^{\circledR}$ and Lucie Delaunay, ${ }^{*} \dagger$ \\ ${ }^{\dagger}$ Sartorius Stedim FMT S.A.S, Z.I. Les Paluds, Avenue de Jouques CS91051, 13781 Aubagne Cedex, France \\ ${ }^{\ddagger}$ Aix Marseille Univ, Avignon Université, CNRS, IRD, IMBE, Marseille, France \\ ${ }^{\S}$ Aix Marseille Univ, CNRS, ICR, case 551, 13397 Marseille, France
}

ABSTRACT: Polymers such as polyethylene (PE) and ethylene vinyl alcohol (EVOH) are primary constituents of multilayer films used in the food and biopharmaceutical packaging. In order to explore the film behavior after gamma-sterilization, several tests are performed (tensile tests, differential scanning calorimetry (DSC), oxygen transmission rate (OTR) and water vapor transmission rate (WVTR). The investigation of the $\mathrm{PE} / \mathrm{EVOH} / \mathrm{PE}$ multilayer film is done at several gamma-irradiation doses up to $270 \mathrm{kGy}$. For irradiation dose up to $50 \mathrm{kGy}$, mechanical properties are not

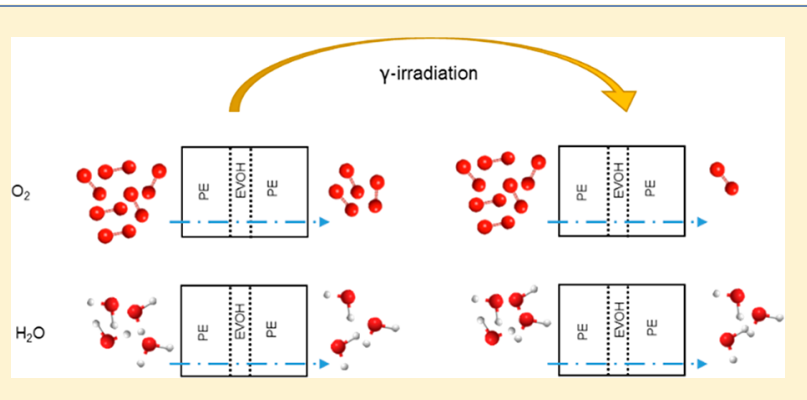
altered. Whatever the irradiation dose, water barrier in $\mathrm{PE} /$

$\mathrm{EVOH} / \mathrm{PE}$ multilayer film is not altered whereas the oxygen barrier property is increased by $300 \%$. This enhancement is shown not to occur due to reorientation, closer chain packaging and restriction of chain mobility of polymer chains in the amorphous phase of the different polymers. This enhancement rather comes from a change of the chemical environment of the EVOH layer.

\section{INTRODUCTION}

Over the past several decades, multilayer packaging films are studied more and more due to their very easy use (long shelf life and mechanical properties), easy preparation, and convenient storage properties (oxygen and water barriers). For a number of various uses (storage, mixing, freezing, transportation, formulation, and filling), biopharmaceutical solutions are stored in sterile, single-use plastic bags, similar to a packaging film. ${ }^{1}$ Single-use bags have been quickly accepted in biopharmaceutical manufacturing worldwide, and they offer a cost-effective alternative to traditional reusable stainless steel systems. Meanwhile, disposable bag technology is well established for cell culture media, buffer, and intermediate storage, but most recently also in cell culture single-use bioreactors used for the production of therapeutic antibodies, proteins, and vaccines. ${ }^{2}$ In food industry they are used to keep nutritive properties of aliments. ${ }^{3}$ Plastic materials are commonly irradiated by $\gamma$ radiation constituting one of the safest ways for microbiological decontamination of raw materials and finished products for pharmaceutical and food packaging film. ${ }^{4}$ The gamma irradiation preserves, for instance, food or prevents the food from developing diseases ${ }^{5}$ by killing cells inside. To be utilized in biopharmaceutical and biotechnology industries, these devices are sterilized with a usual gamma-irradiation dose being from 25 to $45 \mathrm{kGy}^{6}$ In parallel, organizations and regulatory agencies have concluded that irradiated food is safe and wholesome up to $10 \mathrm{kGy}{ }^{7}$

Despite these advantages, plastic film irradiation can produce negative effects such as the alteration of mechanical properties or thermal properties. ${ }^{8}$ For instance, with polyethylene and polypropylene, the loss of useful tensile properties-their extensibility and strength-on exposure to $\mathrm{UV}-\mathrm{B}$ radiation is well-known, ${ }^{9}$ as well as of their average molecular weight. ${ }^{10}$ Indeed, the use of gamma irradiation as sterilizing method implies the occurrence of two mains reactions: bond cleavage and cross-linking, which may dramatically alter the physical properties of the materials. The fundamental events of cross-linking and chain scissions are related to the effect of radiation processes on molecular weight distribution and are well described in the literature. ${ }^{11-13}$ Gamma-sterilization of these systems initiate complex changes inside the material, modifying the additive compounds or damaging the polymers themselves. ${ }^{14}$ Irradiation of polymeric materials has been proven to initiate radical chain reactions inside the polymeric material, ${ }^{15}$ leading to either an increase or a decrease in the polymer molecular weight. ${ }^{16}$ Many inves-

Received: April 19, 2019

Revised: July 12, 2019

Accepted: July 16, 2019

Published: July 16, 2019 
tigations on monolayer films have been conducted. ${ }^{17,18}$ However, little deal with multilayers films and even less are focused on a multi technique approaches. Nevertheless, we expect that the initial reaction will be the same in multilayer film than in respective polyethylene (PE) and polyethylene vinyl alcohol (EVOH) monolayer film. Moreover, very similar chemistry is also expected for the decay of first and second generation radical species. Cross-linking and scission (bond breaking) induce modifications to the matrix environment by introducing connections or branching in the polymer chains (decrease in $-\mathrm{CH}_{2}-$ groups) and breaking polymer chains (increase in $-\mathrm{CH}_{3}$ end groups), respectively (article Raman).

As the cross-linking and chain scission (degradation) could occur at the same time when materials are exposed to radiation, ${ }^{19}$ or in a different ratio or could occur one after the other, monitoring of both effects in the evaluation of radiation resistance could provide an indication of the gammairradiation impact. As cross-linking is the coupling of polymer chains leading to an increase in the molecular weight (MW), this is usually a curing process that modifies the physical and mechanical properties of the polymer and tends to dominate under vacuum and in inert atmospheres. One may consider the mechanical properties drop significantly when the mechanical indices change by $25 \% .{ }^{20}$ Chain scission is the fragmentation of polymer chains leading to a decrease in MW and dominates in the presence of air. In this case migration is expected to increase as lower MW molecules are formed. Some preliminary investigation on similar materials $\mathrm{PE} / \mathrm{EVOH} / \mathrm{PE}$ has been performed a decade ago by Jae Byun et al. for doses lower than $50 \mathrm{kGy} .{ }^{17}$ Mechanical properties were altered a few percent.

In addition to the mechanical strength, materials for plastic packaging should possess various other characteristics such as high barrier requirement, heat resistance, puncture resistance, chemical resistance, transparency, gloss, compliance with relevant pharmaceutical and food contact regulations, etc. ${ }^{21}$ Indeed, an important characteristic of multilayer film packaging is the oxygen permeability, ${ }^{22}$ as biopharmaceutical solutions stored in sterile single-use plastic bags could be sensitive to oxygen. The most common retortable plastic disposable bag technology are thermoformed from coextruded multilayer structures consisting of polyolefins (e.g., polypropylene (PP) and $\mathrm{PE}$ ), at the surfaces, with an internal oxygen barrier layer, such as, presently, the EVOH. The traditional oxygen barrier material in flexible over pouches has been aluminum in the form of sheets of a few micrometers thickness and as metallization. ${ }^{23}$ Aluminum foil provides the ultimate gas and moisture barrier in flexible packages when it is used at thickness larger than $25.4 \mu \mathrm{m}$. $^{24}$ However, when used in smaller thicknesses it is susceptible to the formation of pinholes and other stress induced fractures such as flex crack. Additionally, foil-based packaging results in nonrecyclable material, generating excess waste. Other limitations of aluminum foil include lack of transparency (product visibility). $^{25}$

In a series of articles, we addressed the effect of gamma irradiation on chemical modifications of the materials using various techniques ( $\mathrm{pH}$ analyses, ${ }^{1}$ Fourier transformation infrared spectroscopy, ${ }^{26}$ RAMAN spectroscopy, ${ }^{27}$ and X-ray photoelectron spectroscopy ${ }^{28}$ ) where the generation of oxidized species were detected in surface and in depth of materials. Moreover, an EPR investigation ${ }^{15}$ showed the presence of radical species in EVOH layer of $\mathrm{PE} / \mathrm{EVOH} / \mathrm{PE}$ multilayer film despite the presence of various radical scavengers. All these observations led us to investigate the physical and mechanical properties of the multilayer film, including the thermal properties, the stretching behavior, and the oxygen and water permeability, which might be altered by gamma irradiation.

The effect of gamma irradiation on the oxygen permeability can be partially explained by reorientation in the EVOH polymer, closer chain packaging, and restriction of chain mobility of polymer chains in the amorphous phase. Reorientation and crystallization are related to alter sorption and diffusion of oxygen in polymer materials and might cause a decrease of the oxygen permeability. ${ }^{24}$ In the literature, the effect of gamma irradiation on the permeabilities properties depend on the polymer studied. No effect was measured at low dose for polyolefins films, ${ }^{29}$ but significant decrease was observed for EVOH film. ${ }^{17}$ They reported a $300 \%$ improvement in $\mathrm{O}_{2}$ barrier property of EVOH which was ascribed to the cross-linking between polymer chains. Similar results have been reported by Lopez-Rubio. ${ }^{30}$

In this paper, the objectives were to determine the effects of gamma-irradiation of $0-270 \mathrm{kGy}$ on physicochemical characteristics, such as oxygen and water permeabilities, mechanical properties, and thermal properties of $\mathrm{PE} / \mathrm{EVOH} / \mathrm{PE}$ packaging film. Generally, the low doses such as 10 and $50 \mathrm{kGy}$ are being used in industrial sterilization process of pharmaceutical application devices. However, the effects of gamma-irradiation at high dose up to $270 \mathrm{kGy}$ were adopted in order to explore and accentuate minor differences.

\section{MATERIALS AND METHODS}

2.1. PE/EVOH/PE Multilayer Film. The PE/EVOH/PE multilayer film is composed of two layers of linear low-density polyethylene (LLDPE) and one layer of EVOH (copolyethylene vinyl alcohol) with $71 \mathrm{~mol} \%$ of $-\mathrm{VOH}$. The two PE layers correspond to the external and the contact layer and the EVOH layer corresponds to the internal layer. The total thickness of film is about $400 \mu \mathrm{m}$ with an internal PE layer of $235 \mu \mathrm{m}$, an EVOH layer of $25 \mu \mathrm{m}$, and an external PE layer of $100 \mu \mathrm{m}$. A significant thickness is necessary to safely reach biotechnological and biopharmaceutical applications with heavy storage volume up to $3000 \mathrm{~L}$. These materials and structure must then stay robust and flexible for these applications requesting high flex-stress feature. Additives (especially phenol and phosphite ${ }^{31-33}$ ) are included in different layers of this film for their stabilization during the manufacturing process and during their shelf life. The structure of the entire film is depicted in Figure 1.

Four batches of $\mathrm{PE} / \mathrm{EVOH} / \mathrm{PE}$ multilayer film are investigated. For the tensile test results, only one lot is displayed. Different structural features according to machine direction (MD) and transversal direction (TD) due to extrusion process are displayed. For the DSC results, the average of the four batches is reported and for oxygen and water vapor transmission rates, three batches are tested. For nondisplayed and nondiscussed batches, results are similar.

2.2. Gamma-Irradiation. Samples of $\mathrm{PE} / \mathrm{EVOH} / \mathrm{PE}$ multilayer film have been irradiated at room temperature in a ${ }^{60} \mathrm{Co}$ gamma-source. This ${ }^{60} \mathrm{Co}$ gamma-source provides a dose rate of $8-13 \mathrm{kGy} / \mathrm{h}$ - as given by the company Synergy Health Marseille (France), affording doses of $30( \pm 1), 50$ $( \pm 1), 115( \pm 2)$, and $270( \pm 5) \mathrm{kGy}$. A sterilization cycle provides a dose of $25 \mathrm{kGy}$. To obtain the desired dose, several 


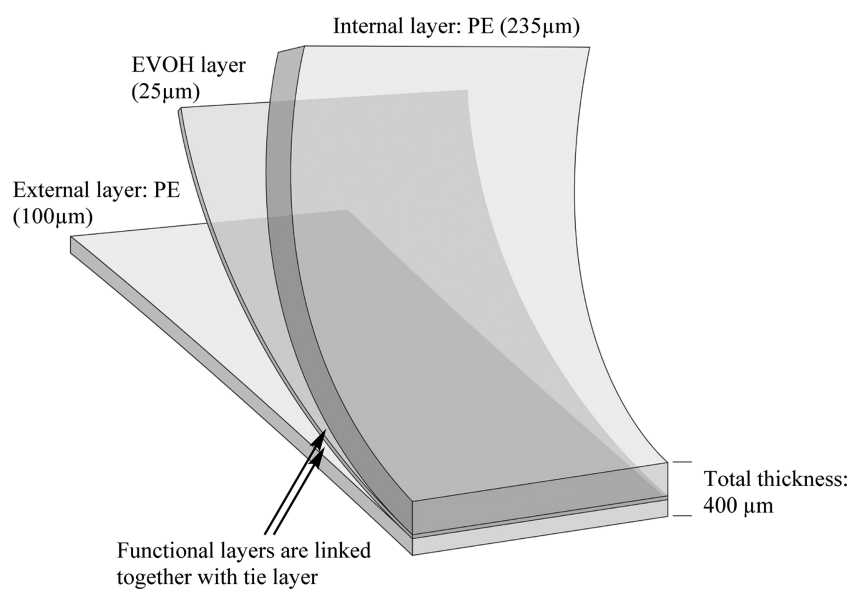

Figure 1. Structure of the $\mathrm{PE} / \mathrm{EVOH} / \mathrm{PE}$ multilayer film.

sterilization cycles were performed. More details are provided in a previous article. ${ }^{34}$

2.3. Tensile Tests. Elongation, ultimate tensile strength (UTS), toughness, and the yields have been measured on the test sample. The tensile properties were measured in two directions: the machine direction (MD) and the transverse direction (TD). The MD corresponds to the direction the film was extruded (direction of the polymer chains), whereas TD is perpendicular to $\mathrm{MD}$.

The mechanical properties of irradiated and nonirradiated films were measured using a universal testing machine (Zwick Z005). The samples were prepared according to ISO527-3 norms $^{35}$ (150 mm length, $15 \mathrm{~mm}$ width). The crosshead speed used was $500 \mathrm{~mm} / \mathrm{min}$. The initial gauge length was $100 \mathrm{~mm}$. Five specimens per direction were at least performed for each sample. Tensile strength tests were measured at $23 \pm 3{ }^{\circ} \mathrm{C}$ and at $1 \mathrm{~atm}$. Four sample batches have been investigated. Results are displayed for one batch (Figure 2, Figure 3) and all replicates for each batch are reported in SI (Figure S1). The statistical errors represented in Figure 3a,b are calculated with the replicates.

Ultimate tensile strength (UTS) is then determined as the maximum stress the material can withstand and is calculated by dividing the maximum load by the original cross-sectional area of the specimen. The latter is recorded at the moment of sample rupture. Toughness as per ASTM D882, ${ }^{36}$ is also calculated as the resistance to fracture of a material when stressed. The toughness (or tensile energy at break, TEB) is the combination of the UTS and the elongation and is defined by the area under the stress-strain curve (Figure 2) considering the volume sample. The toughness is given as eq 1 .

$$
\mathrm{TEB}=\int_{0}^{\epsilon_{T}} S d \epsilon
$$

Where $S$ is the stress at any strain, $\epsilon$, and $\epsilon_{\mathrm{T}}$ is the strain at rupture. ${ }^{36}$

2.4. DSC (Differential Scanning Calorimetry). The melting temperature of each polymer which composed the films are determined using differential scanning calorimetry (DSC). Samples (30-40 mg) of $\mathrm{PE} / \mathrm{EVOH} / \mathrm{PE}$ multilayer film nonirradiated and irradiated at different gamma-doses are introduced in the DCS device. Measurements are performed with a calorimeter Sensys Evo Setaram. The range of heating is $23-250{ }^{\circ} \mathrm{C}$, and the heating rate was $10{ }^{\circ} \mathrm{C} / \mathrm{min}$. During the DSC experiments, air and $\mathrm{N}_{2}$ are used as the gaseous

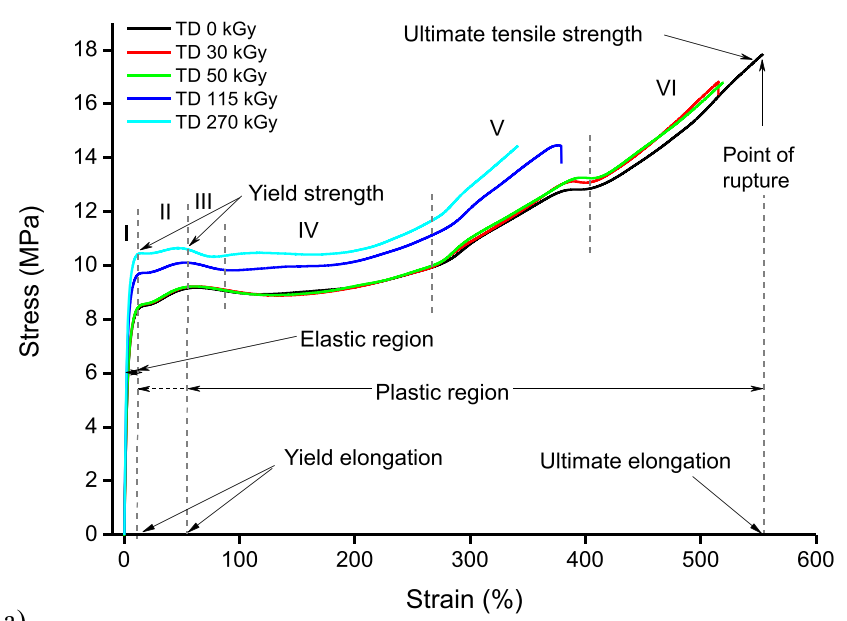

a)

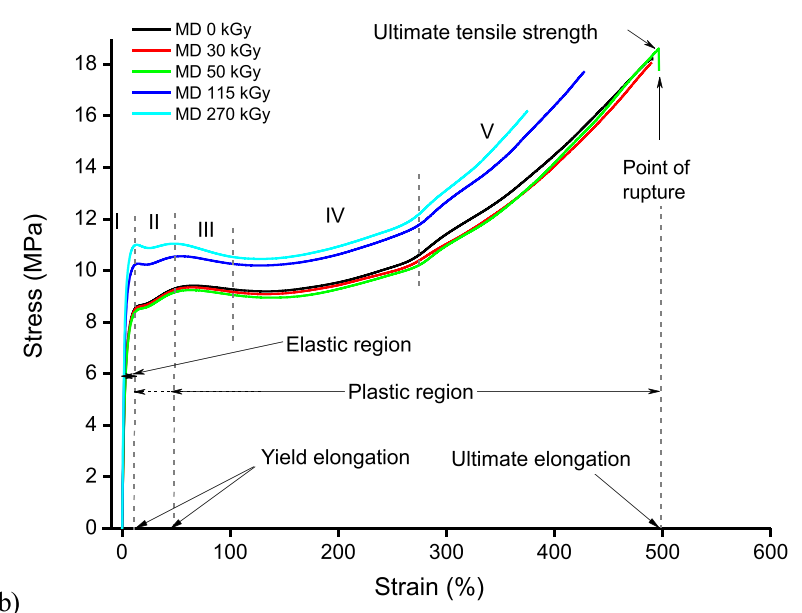

Figure 2. Strain-stress curves of the PE/EVOH/PE multilayer film gamma-irradiated at several doses plotted in transverse direction (TD, a) and in machine direction (MD, b). One curve out of five is displayed here for each testing conditions (gamma-irradiation doses) from one lot. Other lot measurements afforded similar results and plotted in SI.

environments $\left(\mathrm{N}_{2}\right.$ flow: $\left.16 \mathrm{~mL} / \mathrm{min}\right)$. Four sample batches have been investigated. Results are displayed as the average of these four batches (Figure 4a,b). The statistical errors represented are calculated with the four batches. The degree of crystallinity (Figure 5) has been calculated with the second run of heating.

2.5. Oxygen Transmission Rate (OTR). The oxygen transmission rate is measured according the ASTM D3985. ${ }^{37}$ The OTR measures the quantity of $\mathrm{O}_{2}$ which passes through a film surface during $24 \mathrm{~h}\left(\mathrm{~cm}^{3} / \mathrm{m}^{2} / 24 \mathrm{~h}\right)$ at $\mathrm{P}_{\mathrm{O} 2}$ of 0.99 bar. Samples irradiated roughly one month before the test, are kept in the desiccator for $48 \mathrm{~h}$ and installed in the measure device (Mocon OxTran 2.61). Samples are measured several times over time to ensure steady state for each sample. The last value obtained is generally considered as the permeability of the sample. It is a measure at equilibrium. The OTR measurements are performed at $23{ }^{\circ} \mathrm{C}$ and $\sim 0 \% \mathrm{RH}$ (relative humidity) each side of the film. The OTR measurements are carried out from the external to the internal film side. Three sample batches have been investigated. The statistical error has 


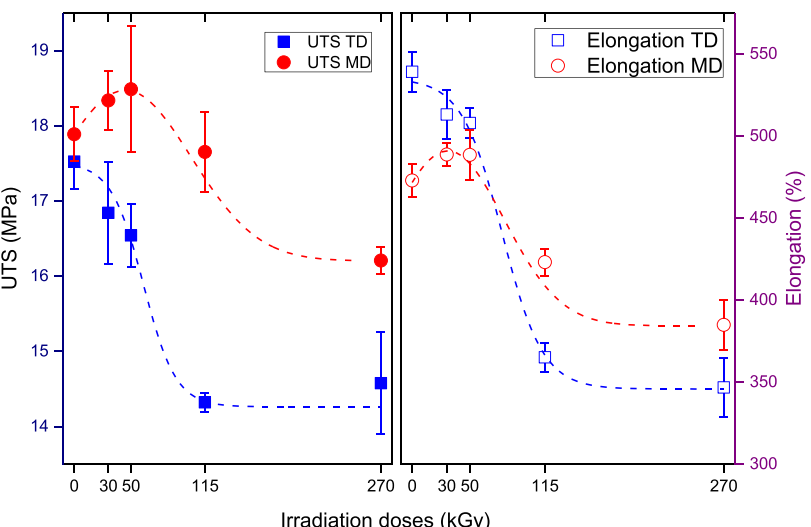

a)

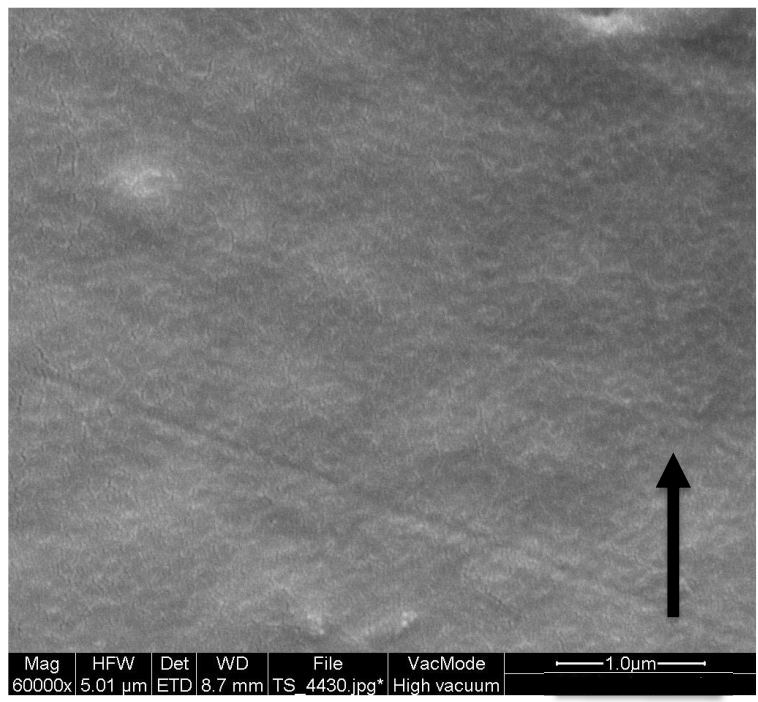

b)

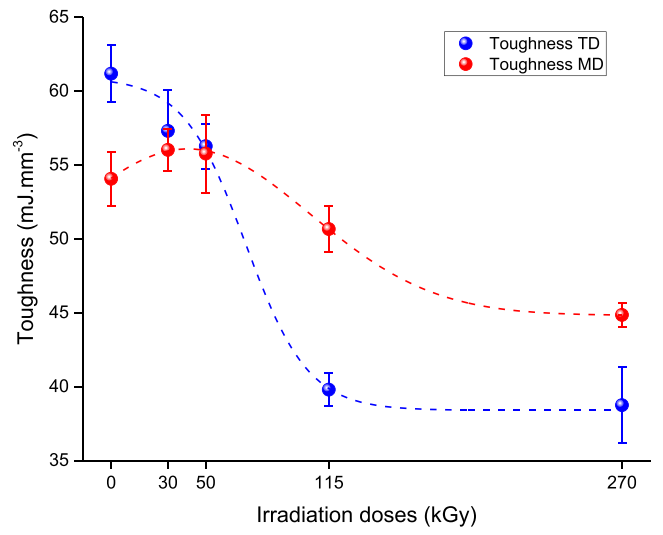

d)

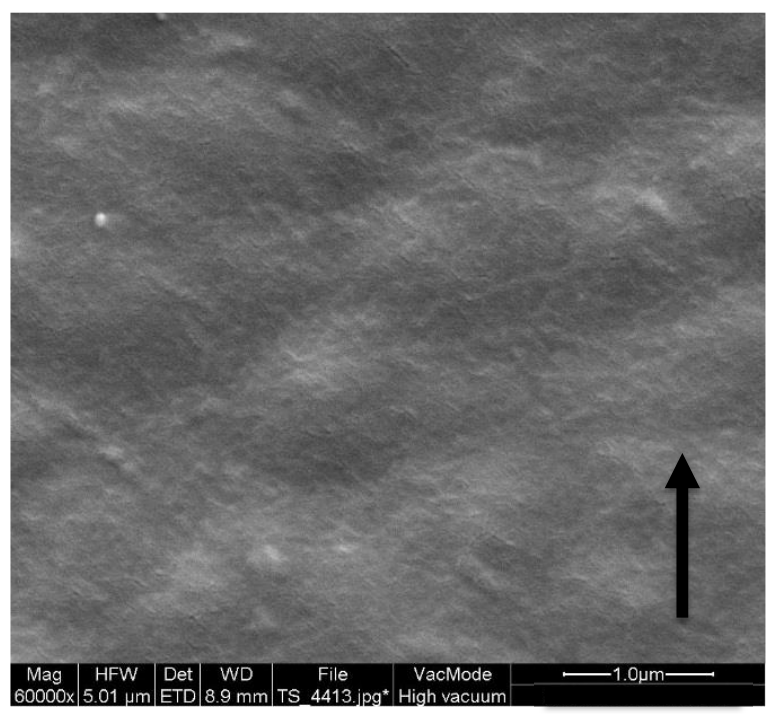

Figure 3. a) (left) Ultimate tensile strength (UTS) for TD (blue solid circles) and MD (red solid circles) and (right) elongation for TD (blue open square) and MD (red open circles) as a function of the gamma-irradiation dose. Fitting curves are here to ease the graph reading. (b) Toughness per TD (blue circles) and MD (red circles) as a function of the gamma-irradiation dose. The fitting curve (dashed lines) are given to ease the reading. (c) SEM picture of the $\mathrm{PE} / \mathrm{EVOH} / \mathrm{PE}$ film irradiated at $270 \mathrm{kGy}$ (internal surface). (d) SEM picture of the nonsterile $\mathrm{PE} / \mathrm{EVOH} / \mathrm{PE}$ film (internal surface). The machine direction $(\mathrm{MD})$ is given by the arrow.

been calculated with the last three measurements of the analysis.

2.6. Water Vapor Transmission Rate (WVTR). The water vapor transmission rate is measured according the ISO $15106-3 .^{38}$ Before the test, samples are kept in an oven at 23 ${ }^{\circ} \mathrm{C}$ and $50 \pm 5 \% \mathrm{RH}$ (relative humidity) for $72 \mathrm{~h}$, minimum. The WVTR measurements are performed at $23{ }^{\circ} \mathrm{C}$ and $\sim 0 \%$ $\mathrm{RH}$ on the external film side and at $23{ }^{\circ} \mathrm{C}$ and $\sim 90 \% \mathrm{RH}$ on the internal film side. The WVTR measurements are carried out from the internal to the external film side. Three sample batches have been investigated with three replicates for each batch. The statistical error has been calculated with the last three measurements of the analysis.

2.7. Scanning Electron Microscopy (SEM). SEM pictures have been recorded on a Quanta 200 apparatus. The samples were sputtered with gold prior to the measurement with calculated gold layer thickness of $\sim 11 \mathrm{~nm}$.The measurement parameters were high-vacuum mode, $12-15 \mathrm{kV}$.

\section{RESULTS}

3.1. Yield. Figure 2 displays the stress-strain curve obtained either in machine direction (MD) or in transversal direction (TD) of the PE-film. The curves displayed in Figure 2 show the same trends of behavior of a flexible polymer with ultimate tensile strength above the yield as defined per ISO527. ${ }^{35}$

Figure 2 shows that the first and the second yield are not impacted by the gamma irradiation in the $0-50 \mathrm{kGy}$ dose range in both film directions. From $115 \mathrm{kGy}$, the first yield increases, and the second yield is strain shifted compared to the first one. The multilayer film is composed of EVOH, which should not be involved in the yield points, and mainly of polyethylene which has a semicrystalline structure and for which the double yielding is well-known in engineering stressstrain curves. ${ }^{39}$

For the nonsterile sample (i.e., $0 \mathrm{kGy}$ ) in transverse direction (Figure $2 \mathrm{a}$ ), two yields, at $\sim 15 \%$ and $\sim 60 \%$ of elongation are observed (phases I-III). Elasticity is kept up to $15 \%$ of film elongation and at $60 \%$ of elongation, and the film in $\mathrm{TD}$ has a residual stretching of $\sim 5 \%$. From $\sim 100 \%$ elongation starts a pseudo plateau to $\sim 285 \%$ elongation (phase IV). Strain hardening is observed from $\sim 285 \%$ (phase V). From $\sim 425 \%$, there is a slope break in the strain hardening which would correspond to the fractioning of the EVOH layer 

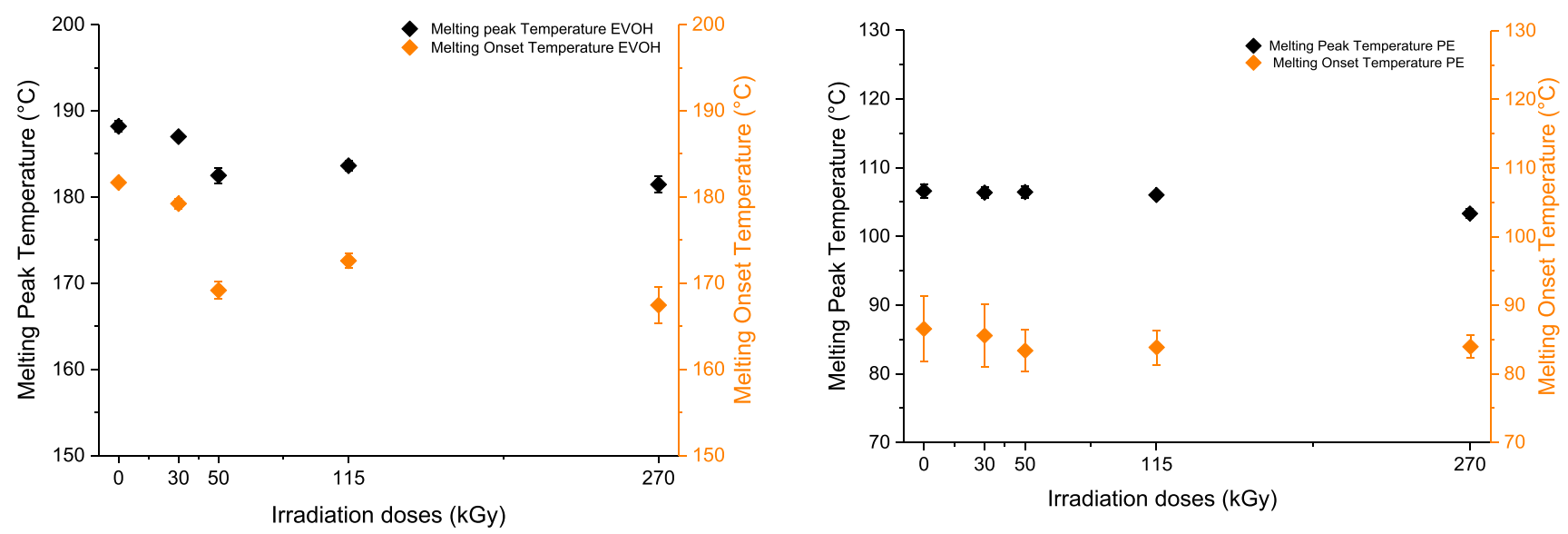

a)

b)
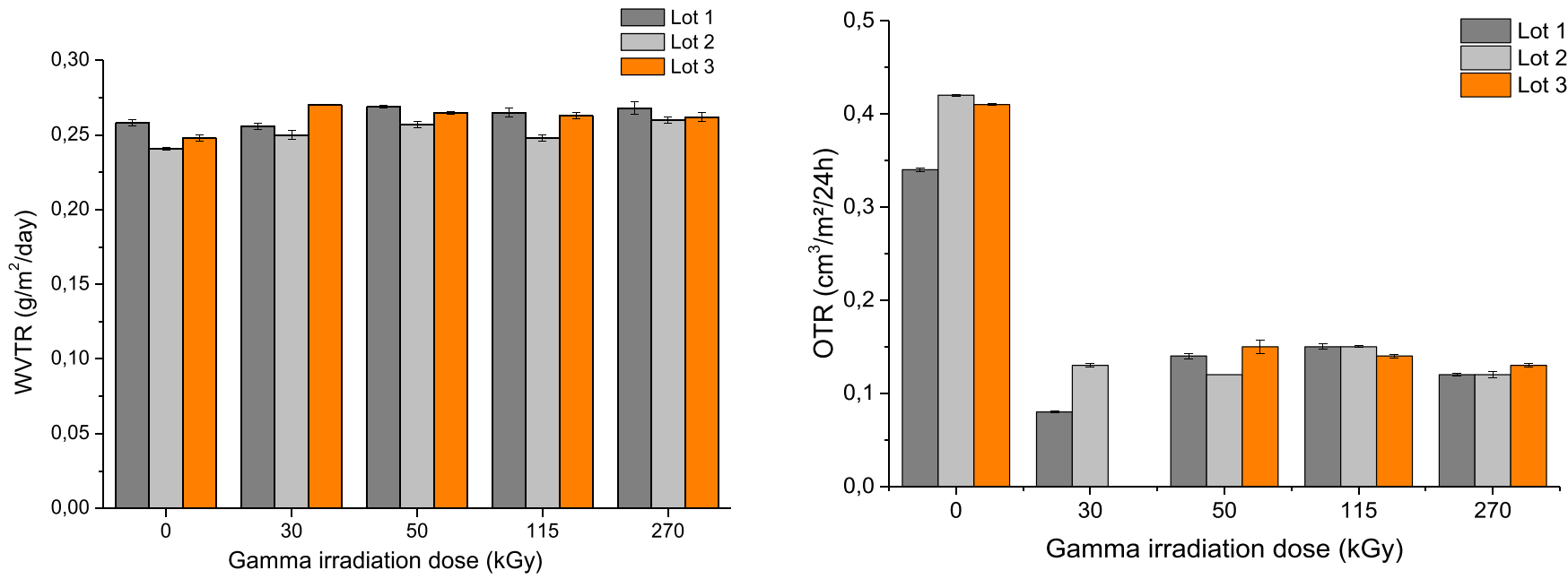

c)

d)

Figure 4. melting points and melting onset points for the EVOH layer (a) and the PE layer (b) used in the PE/EVOH/PE multilayer film according to the gamma-irradiation dose. The average of all film lots is represented for each gamma irradiation dose. And WVTR (c) and OTR (d) of the $\mathrm{PE} / \mathrm{EVOH} / \mathrm{PE}$ film according to the gamma-irradiation dose.

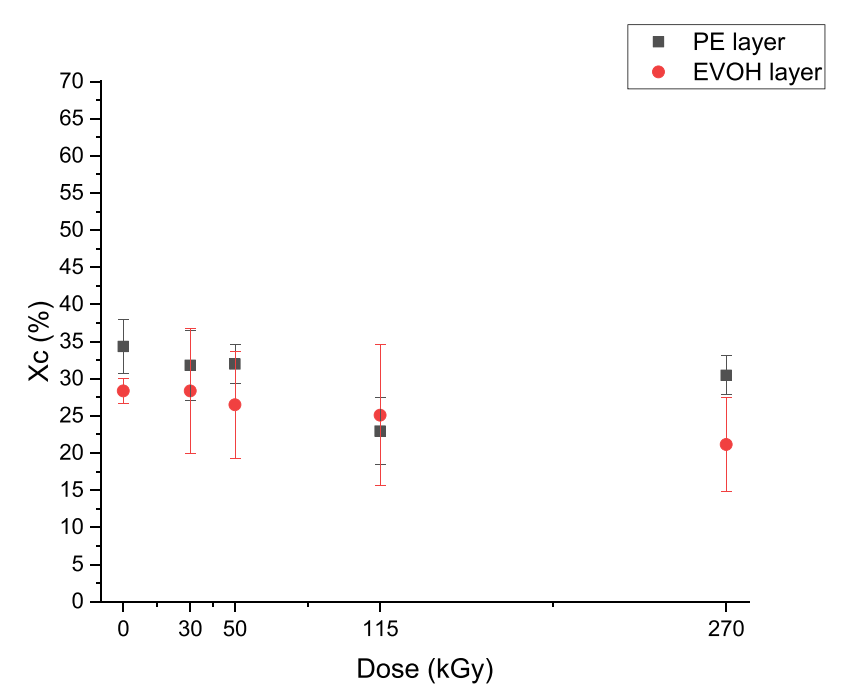

Figure 5. Degree of crystallinity in function of gamma dose for PE layer (black) and EVOH layer (red). until no cohesion remains. After $\sim 425 \%$ elongation, only the inner and outer layers made of $\mathrm{PE}$ participate to the mechanical effort of the stretching until the complete rupture of the film at $550 \%$ (phase VI). Indeed, the EVOH layer cracking was observed after $\sim 425 \%$ by optic microscopic.

For the samples in machine direction (Figure 2b), the main difference between $\mathrm{MD}$ and TD lies thereof on the nonoccurrence of phase VI in MD. The two yields at $\sim 15 \%$ and $\sim 60 \%$ of elongation are still observed, and they still define the phases I to III. Elasticity is kept up to $20 \%$ of film elongation and at $40 \%$ of elongation, the film in MD has a residual stretching of $\sim 3 \%$. From $\sim 100 \%$ elongation starts a pseudo plateau to $\sim 285 \%$ elongation (phase VI). From $\sim 285 \%$ elongation, the strain hardening starts (phase V). After $\sim 285 \%$ elongation, the EVOH layer does not crack in machine direction (MD) and follows the PE layer behavior during strain which mainly participates to the mechanical effort of the stretching until the complete rupture of the film at $500 \%$ (phase V). There is no diminution of the UTS and elongation for the 30-50 kGy doses. For more detailed results descriptions, see SI 


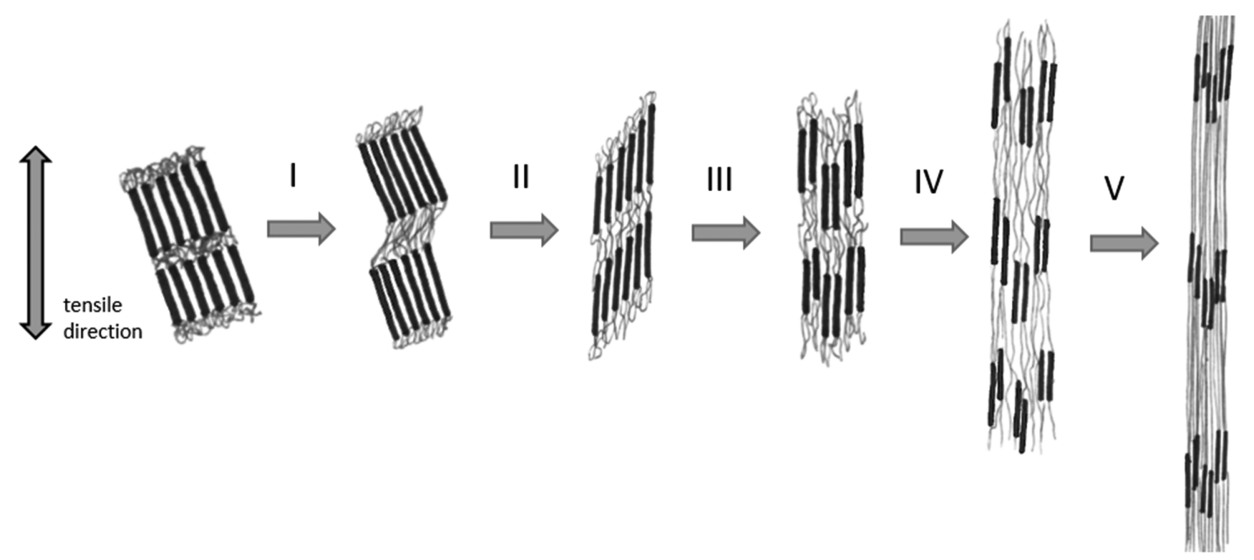

Figure 6. Tensile curve phasing description for the LPDE layer: (I) elastic deformation of the amorphous phase, (II) interlamellar slipping, (III) lamellae fragmentation and coarse slip, (IV) alignment along the tensile direction, whitening phase (necking phase), (V) strain hardening.

3.2. UTS, Elongation and Toughness. The different values obtained for UTS and elongation from the test pieces of one $\mathrm{PE} / \mathrm{EVOH} / \mathrm{PE}$ multilayer film lot irradiated at different gamma-doses are plotted in Figure 3a. Tensile tests were performed on films in machine (MD) and transverse (TD) directions. The measurement of the tensile features on the three other lots afford similar results, and they are not displayed. It is observed in Figure 3a that the PE/EVOH/PE multilayer film presents after irradiation a slight increase in UTS-MD and elongation mode from nonsterile (NS) sample to $50 \mathrm{kGy}(\sim 2 \%)$ doses and a drop is observed for 115 and $270 \mathrm{kGy}$ doses $(\sim 7 \%$ and $\sim 30 \%)$. For UTS and elongation in TD mode, a slight decrease in properties is observed for 30-50 $\mathrm{kGy}$, whereas a clear detrimental effect is observed for higher doses (down from 16.8 MPa until 14.5 MPa for UTS and down from $500 \%$ to $350 \%$ for elongation). This indicates that the whole film becomes less flexible with gamma irradiation. For more detailed results descriptions, see SI.

Synthetic polymers are semicrystalline and contain regions with some order in the arrangement of the polymer chains and disordered amorphous regions. The orientation of the polymer chains in thin films is often anisotropic because of the manufacturing process. In general, tensile strength is greater in a parallel direction to the polymer chains than in perpendicular direction and the same applies to tear resistance. ${ }^{40}$ This anisotropy of the mechanical properties parallel and perpendicular to the processing direction displayed here at 0 $\mathrm{kGy}$ is enhanced up to $270 \mathrm{kGy}$ in favor of the machine direction film features. When comparing mechanical MD and TD film properties (Figure 3a), the elongation is higher in TD than in $\mathrm{MD}$ at weak gamma-irradiation doses $(0-50 \mathrm{kGy})$, with a ratio $\mathrm{TD} / \mathrm{MD}>1$, while this trend is described inverted at high gamma-irradiation doses ( $>50-270 \mathrm{kGy})$; the TD/MD ratio is $\sim 0.9$. This is described by the way of elongation which influences the polymer chains in which no preferred orientation for spherulites is observed and in which no impact of the gamma irradiation is likewise observed (Figure 3c,d).

In addition, the behavior of the toughness for MD follows directly the slight modification of the elongation for $\mathrm{MD}$ induced by the gamma-irradiation (Figure 3a). The loss of the toughness for TD is directly related to the decrease of the UTS and to elongation at the highest irradiation doses (Figure $3 \mathrm{~b}$ ). The drop of the tensile properties in the transverse direction (TD) becomes obvious from $150 \mathrm{kGy}$.
3.3. Thermal Properties and OTR-WVTR. Regarding the DSC results evaluating the thermal properties, it appears that the $\mathrm{EVOH}$ layer melting temperature drops from $\sim 190{ }^{\circ} \mathrm{C}$ at 0 $\mathrm{kGy}$ down to $\sim 180{ }^{\circ} \mathrm{C}$ at $270 \mathrm{kGy}$ (Figure $4 \mathrm{a}$ ). Looking to the $\mathrm{PE}$ layers, there is no modification of the melting points (Figure 4b). Consequently, irradiation does not alter significantly (not significant amount of cross-linking and chain breaking events) the structure composition of $\mathrm{PE}$ whereas this effect is more pronounced for EVOH. That is, a drop of $10{ }^{\circ} \mathrm{C}$ in the melting temperature (Tm) denotes a slight degradation of the EVOH layer likely due to chain breaking or alteration of the H-bonding network. This slight degradation could not be detected by differential scanning calorimetry via a change of the glass transition ( $\mathrm{Tg}$ ) temperature of the EVOH. Examples of thermograms (all doses) are displayed in SI Figures S2-S6, and the same observations are done for all batches and doses.

Permeability to gases depends on crystallinity, chain length, chemical modifications, cross-linking, and cohesive energy density (CED). It is commonly accepted that permeability to water or oxygen decreases strikingly or even dramatically when one of the mentioned properties is increased..$^{41}$ Noteworthily, it is commonly accepted that $\mathrm{EVOH}$ exhibits the most efficiency barrier to $\mathrm{O}_{2}$ due to the tight $\mathrm{H}$-bonding network, tremendously reducing the free volume between chains as well as their mobility, one of the properties needed for good permeability. $\mathrm{PE}$ is one of the most efficient polymers as barrier for water due to its hydrophobicity. The absence of significant difference in permeability of water, whatever the irradiation doses, means that changes in PE layers are not yet enough to alter the barrier property of these layers (Figure 4c). On the other hand, despite materials only degraded at irradiation doses larger than $50 \mathrm{kGy}, \mathrm{O}_{2}$ barrier properties do not depend on doses and is, surprisingly, strikingly improved, that is, 300\% more efficient for irradiated batches than for nonsterile batches (Figure 4d). No change of crystallinity has been measured by differential scanning calorimetry (DSC) and confirmed with FTIR. $^{26}$ Moreover, to correlate the crystallinity and permeability properties, the degree of crystallinity (Xc) has been calculated for PE layer and EVOH layer with the eq 2. $\Delta H_{\mathrm{m}}$ (enthalpy of melting) has been calculated with DSC curves (see SI). $\Delta H_{\mathrm{m}}{ }^{0}=290 \mathrm{~J} / \mathrm{g}$ for $100 \%$ crystalline $\mathrm{PE}^{42}$ and $\Delta \mathrm{Hm}^{0}$ $=150 \mathrm{~J} / \mathrm{g}$ for $100 \%$ crystalline PVOH. ${ }^{43}$ 


$$
\mathrm{Xc}(\%)=\frac{\Delta H_{\mathrm{m}}}{\Delta H_{\mathrm{m}}^{0}} \times 100
$$

The degree of crystallization in function of gamma dose is displayed in Figure 5. Gamma irradiation induces a change of $5 \%$ of crystallinity for EVOH and PE layers. In this work, the crystallinity seems not to be related to the generation of $\mathrm{O}_{2}$ barrier properties. Indeed, 5\% of crystallinity is unlikely significant enough to induce a $300 \% \quad \mathrm{O}_{2}$ barrier property enhancement with gamma irradiation.

\section{DISCUSSION}

4.1. Mechanical Properties. Tensile testing provokes an orientation of the chains. If a mass of randomly coiled and entangled chains is at a temperature high enough when strain is applied, as in biaxial stretching, the polymer chains disentangle, unfold, and straighten, and slip past their nearest neighbor. ${ }^{44}$ At temperatures higher than the glass temperature, PEs become more flexible and can unfold as strain is applied. It is not the case of the EVOH $\left(\mathrm{Tg} \sim 60{ }^{\circ} \mathrm{C}\right)$. The UTS is higher for film stressed in MD because of the frictions occurring between chains during the strain, without necessarily providing a higher resistance to rupture compared to TD. The cohesive force between chains in TD is not necessarily destroyed during strain (Figure 2). This could indicate that globally the environment in the $\mathrm{PE}$ chains are not changed by the gamma irradiation.

Differences in the two yield evolution during gamma irradiation are not clear enough to afford a meaningful discussion. However, there are several hypotheses. Several approaches suggest that the first yield is due to slip of fine LLDPE chains through the lamellae (phases I \& II in Figure 6) and the second due to a coarse slip resulting in lamellae fragmentation ( $\geq$ phases III in Figure 6). ${ }^{45-47}$ One knows that cross-linking and chain scission can occur during gamma irradiation leading us to think about two hypotheses to explain the changes in the first and second yields. In a first assumption, where the cross-linking is considered to be predominant in the LLDPE layer, the amorphous phase is impacted, and no further cross-linking occurs inside the lamellae. The whole material would become less flexible. The first yield will then increase while the second yield will remain unchanged. In the second assumption where the chain scission is considered to be predominant in the LLDPE layer, the proportion of small thin chains would increase during the gamma irradiation, leading to the increase of slipping through lamellae before fragmentation. Fragmentation strength could remain the same. This phenomenon clearly discloses the brittle and the ductile nature of the first and the second yield, respectively. ${ }^{48}$ Looking back to the results depicted in Figures 2 and 3, it means that the gamma irradiation mainly impacts the amorphous phase by cutting "fine" chains making the materials more brittle. The gamma irradiation makes increase the first yield and decrease the UTS and elongation. A potential chain rearrangement could be possible, making globally the material less flexible. This is a second indication that there is no change in the network environment in the PE. Moreover, gamma irradiation does not alter crystallinity of PE layer as the spherulites structures are not modified at the surface of PE layer before and after sterilization (Figure 3c,d). One may have assumed that observation hold for internal PE layer.

The absence of change in the thermal properties for PE denotes the absence of significant alteration in structuration (molecular size and cross-linking) in nice agreement with mechanical properties. On the other hand, for doses larger than $50 \mathrm{kGy}$, a $10{ }^{\circ} \mathrm{C}$ drop of $\mathrm{Tm}$ for $\mathrm{EVOH}$ is noted pointing at structural changes such as chain breaking or destruction of the $\mathrm{H}$-bonding network. Nevertheless, these alterations of the EVOH layer do not impact significantly the mechanical properties. Moreover, no significant changes in $\mathrm{Tm}$ are observed for irradiation doses lower than $50 \mathrm{kGy}$.

The whole mechanical resistance of the film to various strains is due to the contribution of all layers of the film. The inner and outer layers made of polyethylene mainly contributes to the overall resistance of the network while the EVOH layer will tend to break earlier even though $\mathrm{H}$-bonding are present between $\mathrm{EVOH}$ chains. Importantly whatever the mechanical properties investigated-yields, tensile, and toughness-no significant alterations are observed for gamma irradiation doses below $50 \mathrm{kGy}$, doses currently applied for sterilization. Such results mean that chain-breaking, cross-linking, and chain ending events are rather rare events at such low doses. A small amount of chain scissions has been previously observed in PE/ $\mathrm{EVOH} / \mathrm{PE}$ multilayer film by infrared spectroscopy ${ }^{26}$ although no significant effect is observed in DSC. On the other hand, these alterations of the materials are more significant for chemical properties such as barrier properties.

4.2. Barriers. Barrier properties to liquid or gases are related to the crystallinity of the materials, the molecular size, the amount of cross-linking between chain, the chemical structure of polymer chain, free volumes, phobicity, and to $\mathrm{H}$ bonding network. ${ }^{17,25,49}$ It is then argued that the permeation of gas molecules occurs due to cooperative movement of the gas molecules and the polymer chain segments. ${ }^{49}$ An alteration of one of these properties affords a lower barrier effect.

Storage of biological solutions in plastic bags requires material exhibition of very high barrier properties to oxygen and water. This aim is reached by preparing multilayer films with an EVOH layer for oxygen barrier $\left(0.16 \times 10^{-5} \mathrm{~cm}^{3} \cdot \mu \mathrm{m} /\right.$ $\mathrm{m}^{2} \cdot$ day $\cdot \mathrm{kPa}$ for PVOH vs 0.038 for $\left.\mathrm{PE}\right)^{41}$ sandwiched by two PE layers as water barrier $\left(100 \mathrm{~cm}^{3} \cdot \mu \mathrm{m} / \mathrm{m}^{2} \cdot\right.$ day $\cdot \mathrm{kPa}$ vs full water solubility for $\mathrm{PVOH}){ }^{41}$ The absence of significant changes in water permeability whatever the irradiation dose is in nice agreement with the absence of significant changes in mechanical properties, Tm of PE layer and crystallinity (Figure $5)$. These results are in sharp contrast with those reported by Fernández. ${ }^{50}$ That is, barrier to $\mathrm{H}_{2} \mathrm{O}$ is $2-3$ times better for 60 $\mathrm{kGy}$ irradiated samples than for nonsterile. However, this result has been observed on monolayer film $\mathrm{EVOH}$ and not for multilayer $\mathrm{PE} / \mathrm{EVOH} / \mathrm{PE}$ for which the barrier is mainly ensured by PE layer.

Indeed, Byun et al. ${ }^{17}$ reported that for irradiated EVOH film, cross-linking is increased, affording a decrease in free volume and hence a slight decrease of $\mathrm{O}_{2}$ permeability upon irradiation, whereas Lopez-Rubio et al. ${ }^{30}$ reports a dramatic effect of $\mathrm{O}_{2}$ barrier for the 60 first hours and a lower barrier effect after $80 \mathrm{~h}$ than for nonsterile materials. On the other hand, a striking 300-percent increase in the $\mathrm{O}_{2}$ barrier is observed whatever the gamma irradiation dose in the sharp contrast with the absence of effect on $\mathrm{H}_{2} \mathrm{O}$ barrier and mechanical properties. Moreover, a drop in Tm for EVOH layer should involve a loss in efficiency in $\mathrm{O}_{2}$ barrier. Surprisingly, all our investigations point out either an absence of change properties for films irradiated at doses lower than 50 $\mathrm{kGy}$ or a decrease in properties for higher doses. However, the oxygen barrier property is strikingly improved whatever the 
irradiation dose. Some controversial results are reported concerning the $\mathrm{O}_{2}$ barrier of EVOH after irradiation.

Noteworthy, few years ago, we reported the detection of hydroxy alkyl radicals in the EVOH layer of the same PE/ EVOH/PE multilayer film using EPR technics. ${ }^{15}$ Alkyl radicals are well-known to efficiently scavenge $\mathrm{O}_{2}$ generating alkyl peroxyl radicals (Figure 7). The latter is prone to attract labile

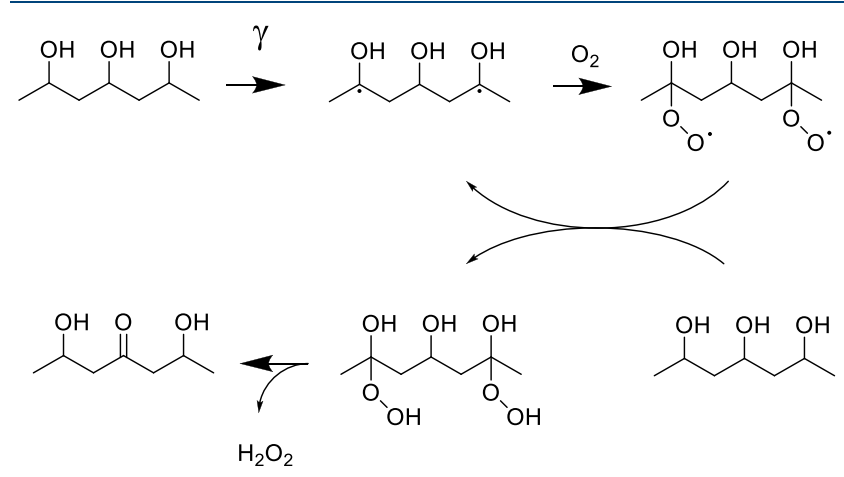

Figure 7. Formation of oxygenated species and alkyl radicals from EVOH layer.

$\mathrm{H}$ atom in position $\alpha$ to hydroxy group $\left(\mathrm{BDE}\left(\mathrm{RCH}_{2}-\mathrm{R}\right)=\right.$ $410 \mathrm{~kJ} / \mathrm{mol}$ vs $\mathrm{BDE}(\mathrm{CHOH})=396 \mathrm{~kJ} / \mathrm{mol})$ regenerating a new alkyl radical perpetuating the barrier effect.

This enhanced barrier effect due to the presence of radical has been proposed by Lopez-Rubio et al. ${ }^{30}$ but not confirmed by EPR. On the other hand, this enhanced $\mathrm{O}_{2}$ barrier effect has been observed and in the presence of radicals confirmed by EPR in the case of PMMA and PVA. ${ }^{51,52}$ Consequently, literature supports nicely our claims.

\section{CONCLUSION}

In the present study, the attention was focused on the mechanical and barrier properties to explore and to understand the film behavior after gamma-sterilization. The study has shown that the $\mathrm{PE} / \mathrm{EVOH} / \mathrm{PE}$ multilayer film undergoes no significant structural modification (i.e., <25\%) under $50 \mathrm{kGy}$ in comparison to the nonirradiated specimens.

The tensile strength testing and the oxygen permeability show, on the one hand, that the EVOH layer is impacted by the gamma-irradiation which can be detrimental for the whole web behavior at high doses (i.e., $\geqslant 115 \mathrm{kGy}$ ). Indeed, a striking $300 \%$ increase in $\mathrm{O}_{2}$ barrier property is observed with gamma irradiation. This observation is due to the formation of alkyl radicals scavenging $\mathrm{O}_{2}$ and then provoking the enhancement of the oxygen permeability. On the other hand, the thermal property measurement performed by DSC pointed out that the $\mathrm{PE}$ layer is not impacted during the gamma-irradiation. Hence, the water permeability of the $\mathrm{PE} / \mathrm{EVOH} / \mathrm{PE}$ multilayer film remains constant with gamma irradiation as the chain network is not structurally and chemically modified by the gammairradiation. Both tensile strength and thermal properties are indeed linked, whereas the sensitivity of both analytical tools are not equal. For instance, a slight change in cross-linking is exacerbated during the tensile test.
More information regarding tensile test principle, tensile test results, and DSC (differential scanning calorimetry) thermograms (PDF)

\section{ACKNOWLEDGMENTS}

We acknowledge Sartorius Stedim FMT S.A.S. for the financial support of this work.

\section{REFERENCES}

(1) Dorey, S.; Gaston, F.; Dupuy, N.; Barbaroux, M.; Marque, S. R. A. Reconciliation of $\mathrm{pH}$, conductivity, total organic carbon with carboxylic acids detected by ion chromatography in solution after contact with multilayer films after $\gamma$-irradiation. Eur. J. Pharm. Sci. 2018, 117, 216.

(2) Jurkiewicz, E.; Husemann, U.; Greller, G.; Barbaroux, M.; Fenge, C. Verification of a new biocompatible single-use film formulation with optimized additive content for multiple bioprocess applications. Biotechnology progress 2014, 30, 1171.

(3) Turan, D.; Sängerlaub, S.; Stramm, C.; Gunes, G. Gas permeabilities of polyurethane films for fresh produce packaging: Response of $\mathrm{O} 2$ permeability to temperature and relative humidity. Polym. Test. 2017, 59, 237.

(4) Salafranca, J.; Clemente, I.; Isella, F.; Nerín, C.; Bosetti, O. Influence of oxygen and long term storage on the profile of volatile compounds released from polymeric multilayer food contact materials sterilized by gamma irradiation. Anal. Chim. Acta 2015, 878, 118.

(5) Pentimalli, M.; Capitani, D.; Ferrando, A.; Ferri, D.; Ragni, P.; Segre, A. L. Gamma irradiation of food packaging materials: An NMR study. Polymer 2000, 41, 2871.

(6) The Irradiation and Sterilization Subcommittee of the BioProcess Systems Alliance. Guide to Irradiation and Sterilization Validation of Single-Use Bioprocess Systems. https://bioprocessintl. com/upstream-processing/upstream-single-use-technologies/guideto-irradiation-and-sterilization-validation-of-single-use-bioprocesssystems-183975/.

(7) Morehouse, K. M.; Komolprasert, V. Irradiation of Food and Packaging: An Overview. In Irradiation of Food and Packaging; Komolprasert, V., Morehouse, K. M., Eds.; ACS Symposium Series; American Chemical Society: Washington, DC, 2004; pp 1-11.

(8) Sun, Y.; Chmielewski, A. G. Applications of Ionizing Radiation in Materials Processing; Institute of Nuclear Chemistry and Technology: Warszawa, 2017.

(9) Hamid, S. H.; Amin, M. B. Lifetime prediction of polymers. J. Appl. Polym. Sci. 1995, 55, 1385.

(10) Andrady, A. L.; Pegram, J. E.; Tropsha, Y. Changes in carbonyl index and average molecular weight on embrittlement of enhancedphotodegradable polyethylenes. J. Environ. Polym. Degr. 1993, 1, 171.

(11) Charlesby, A. Proceeding of the Royal Society 1954, A222.

(12) Saito, O. Effects of High Energy Radiation on Polymers II. Endlinking and Gel Fraction. J. Phys. Soc. Jpn. 1958, 13, 1451. 
(13) Saito, O. On the Effect of High Energy Radiation to Polymers I. Cross-linking and Degradation. J. Phys. Soc. Jpn. 1958, 13, 198.

(14) Stoffers, N. H.; Linssen, J. P.H.; Franz, R.; Welle, F. Migration and sensory evaluation of irradiated polymers. Radiat. Phys. Chem. 2004, 71, 205.

(15) Audran, G.; Dorey, S.; Dupuy, N.; Gaston, F.; Marque, S. R.A. Degradation of $\gamma$-irradiated polyethylene-ethylene vinyl alcoholpolyethylene multilayer films: An ESR study. Polym. Degrad. Stab. 2015, 122, 169.

(16) Demertzis, P. G.; Franz, R.; Welle, F. The effects of $\gamma$ irradiation on compositional changes in plastic packaging films. Packag. Technol. Sci. 1999, 12, 119.

(17) Jae Byun, Y.; Hong, S. I.; Kim, K. B.; Jeon, D. H.; Kim, J. M.; Whiteside, W. S.; Jin Park, H. Physical and chemical properties of $\gamma$ irradiated EVOH film. Radiat. Phys. Chem. 2007, 76, 974.

(18) Jeon, D. H.; Lee, K. H.; Park, H. J. The effects of irradiation on physicochemical characteristics of PET packaging film. Radiat. Phys. Chem. 2004, 71, 1059.

(19) Chapiro, A. Radiation Chemistry of Polymers. Radiat. Res., Suppl. 1964, 4, 179.

(20) Ivanov, V. S. Radiation Chemistry of Polymers; $w$ Concepts in Polymer Science; VSP: Utrecht, 1992.

(21) Sidwell, J. A. Food Contact Polymeric Materials,Vol. 6, No. 1. Report 61. Rapra Technology,1992.

(22) Buntinx, M.; Willems, G.; Knockaert, G.; Adons, D.; Yperman, J.; Carleer, R.; Peeters, R. Evaluation of the Thickness and Oxygen Transmission Rate before and after Thermoforming Mono- and Multi-layer Sheets into Trays with Variable Depth. Polymers 2014, 6, 3019.

(23) Lange, J.; Wyser, Y. Recent innovations in barrier technologies for plastic packaging?: A review. Packag. Technol. Sci. 2003, 16, 149.

(24) Robertson, G. L. Food Packaging: Principles and Practice, 3rd ed.; CRC Press: Boca Raton FL, 2013.

(25) Mokwena, K. K.; Tang, J. Ethylene vinyl alcohol: a review of barrier properties for packaging shelf stable foods. Crit. Rev. Food Sci. Nutr. 2012, 52, 640.

(26) Gaston, F.; Dupuy, N.; Marque, S. R.A.; Barbaroux, M.; Dorey, $\mathrm{S}$. One year monitoring by FTIR of $\gamma$-irradiated multilayer film PE/ EVOH/PE. Radiat. Phys. Chem. 2016, 125, 115.

(27) Gaston, F.; Dupuy, N.; Marque, S. R.A.; Dorey, S. Evaluation of multilayer film stability by Raman spectroscopy after gammairradiation sterilization process. Vib. Spectrosc. 2018, 96, 52.

(28) Dorey, S.; Gaston, F.; Marque, S. R.A.; Bortolotti, B.; Dupuy, N. XPS analysis of PE and EVA samples irradiated at different $\gamma$-doses. Appl. Surf. Sci. 2018, 427, 966.

(29) George, J.; Kumar, R.; Sajeevkumar, V. A.; Sabapathy, S. N.; Vaijapurkar, S. G.; Kumar, D.; Kchawahha, A.; Bawa, A. S. Effect of $\gamma$ irradiation on commercial polypropylene based mono and multilayered retortable food packaging materials. Radiat. Phys. Chem. 2007, 76, 1205.

(30) López-Rubio, A.; Lagarón, J. M.; Yamamoto, T.; Gavara, R. Radiation-induced oxygen scavenging activity in EVOH copolymers. J. Appl. Polym. Sci. 2007, 105, 2676.

(31) Jeon, D. H.; Park, G. Y.; Kwak, I. S.; Lee, K. H.; Park, H. J. Antioxidants and their migration into food simulants on irradiated LLDPE film. Food Sci. Technol. 2007, 40, 151.

(32) Bourges, F.; Bureau, G.; Dumonceau, J.; Pascat, B. Effects of electron beam irradiation on antioxidants in commercial polyolefins: Determination and quantification of products formed. Packag. Technol. Sci. 1992, 5, 205.

(33) Pospísil, J. Chemical and photochemical behaviour of phenolic antioxidants in polymer stabilization-a state of the art report, Part I. Polym. Degrad. Stab. 1993, 40, 217.

(34) Gaston, F.; Dupuy, N.; Marque, S. R.A.; Barbaroux, M.; Dorey, S. FTIR study of ageing of $\gamma$-irradiated biopharmaceutical EVA based film. Polym. Degrad. Stab. 2016, 129, 19.

(35) ISO527. Plastics-Determination of tensile properties -- Part 3: Test conditions for films and sheets, 1995 (ISO527-3:1995).
(36) ASTM D882-02. Standard Test Method for Tensile Properties of Thin Plastic Sheeting (ASTM D882-02).

(37) ASTM D3985. Standard Test Method for Oxygen Gas Transmission Rate through Plastic Film and Sheeting Using a Coulometric Sensor (ASTM D3985).

(38) ISO. Plastics, Film and sheeting, Determination of water vapour transmission rate, Part 3: Electrolytic detection sensor method (ISO15106-3).

(39) Duraccio, D.; Mauriello, A.; Cimmino, S.; Silvestre, C.; Auriemma, F.; Rosa, C. de; Pirozzi, B.; Mitchell, G. R. Structureproperty relationships in polyethylene based films obtained by blow molding as model system of industrial relevance. Eur. Polym. J. 2015, 62, 97.

(40) Spragg, R. Measuring Orientation in Polymer Films. http://www. spectroscopyonline.com/measuring-orientation-polymer-films?id= \&pageID $=1 \&$ sk $=\&$ date $=$

(41) Miller, K. S.; Krochta, J. M. Oxygen and aroma barrier properties of edible films: A review. Trends Food Sci. Technol. 1997, 8, 228 .

(42) Kodjie, S. L.; Li, L.; Li, B.; Cai, W.; Li, C. Y.; Keating, M. Morphology and Crystallization Behavior of HDPE/CNT Nanocomposite. J. Macromol. Sci., Part B: Phys. 2006, 45, 231.

(43) Ricciardi, R.; Auriemma, F.; Gaillet, C.; Rosa, C. de; Lauprêtre, F. Investigation of the Crystallinity of Freeze/Thaw Poly(vinyl alcohol) Hydrogels by Different Techniques. Macromolecules 2004, 37, 9510.

(44) Bobovitch, A. L.; Tkach, R.; Ajji, A.; Elkoun, S.; Nir, Y.; Unigovski, Y.; Gutman, E. M. Mechanical properties, stress-relaxation, and orientation of double bubble biaxially oriented polyethylene films. J. Appl. Polym. Sci. 2006, 100, 3545.

(45) Brooks, N. W.; Duckett, R. A.; Ward, I. M. Investigation into double yield points in polyethylene. Polymer 1992, 33, 1872.

(46) Feijoo, J. L.; Sánchez, J. J.; Müller, A. J. The phenomenon of double yielding in blown polyethylene films. Polym. Bull. 1997, 39, 125.

(47) Janssen, R. Deformation and Failure in Semi-Crystalline Polymer Systems. Master Thesis, Eindhoven University of Technology, Eindhoven, 2002.

(48) Séguéla, R.; Darras, O. Phenomenological aspects of the double yield of polyethylene and related copolymers under tensile loading. J. Mater. Sci. 1994, 29, 5342.

(49) Maes, C.; Luyten, W.; Herremans, G.; Peeters, R.; Carleer, R.; Buntinx, M. Recent Updates on the Barrier Properties of Ethylene Vinyl Alcohol Copolymer (EVOH): A Review. Polym. Rev. 2018, 58, 209.

(50) Fernández, A.; Sánchez, M. D.; Ankerfors, M.; Lagaron, J. M. Effects of ionizing radiation in ethylene-vinyl alcohol copolymers and in composites containing microfibrillated cellulose. J. Appl. Polym. Sci. 2008, 109, 126

(51) Kaptan, Y.; Pekcan, Ö.; Arca, E.; Güven, O. Determination of diffusion coefficient of oxygen into polymers by using electron spin resonance spectroscopy. I. Poly(methyl methacrylate). J. Appl. Polym. Sci. 1989, 37, 2577.

(52) Kaptan, Y.; Pekcan, Ö.; Güven, O. Determination of diffusion coefficient of oxygen into polymers by using electron spin resonance spectroscopy. II. Poly(vinyl acetate). J. Appl. Polym. Sci. 1992, 44, 1595. 